\title{
Public Understanding of Science
}

http://pus.sagepub.com

\section{Should we attempt to eradicate disability? \\ John Harris \\ Public Understanding of Science 1995; 4; 233 \\ DOI: $10.1088 / 0963-6625 / 4 / 3 / 002$}

The online version of this article can be found at:

http://pus.sagepub.com/cgi/content/abstract/4/3/233

\author{
Published by: \\ (S)SAGE \\ http://www.sagepublications.com
}

Additional services and information for Public Understanding of Science can be found at:

Email Alerts: http://pus.sagepub.com/cgi/alerts

Subscriptions: http://pus.sagepub.com/subscriptions

Reprints: http://www.sagepub.com/journalsReprints.nav

Permissions: http://www.sagepub.co.uk/journalsPermissions.nav

Citations http://pus.sagepub.com/cgi/content/refs/4/3/233 


\title{
Should we attempt to eradicate disability?
}

\begin{abstract}
John Harris
This paper addresses two very important questions about the ethics of dealing with disability, namely: is it morally wrong to attempt to eradicate disability? and does such an attempt constitute discrimination against the disabled? The attempts to answer these two very general questions involve distinguishing two prior questions: is it wrong to prefer a non-disabled person to a disabled one, and is it wrong to prefer to produce (or even to prefer to be) a non-disabled individual rather than a disabled one? The paper argues that not only is it not wrong, but indeed it is right to prefer to produce a non-disabled individual rather than a disabled one where there is a genuine choice. It argues that the exercise of such a choice is morally defensible and does not constitute discrimination against those with disability, although the contrary is often asserted. The paper concludes that attempts to eradicate disability are not the same as attempts to eradicate the disabled, even where these attempts constitute preferring not to create new individuals with disability.
\end{abstract}

The questions I wish to address here are of very general importance. They are: is it morally wrong to attempt to eradicate disability? Does such an attempt constitute discrimination against the disabled?

\section{Discrimination}

To address the question of possibie discrimination against the disabled we will first need to distinguish two prior questions. They are:

Is it wrong to prefer a non-disabled person to a disabled one?

Is it wrong to prefer to produce (or even to prefer to be) a non-disabled individual rather than a disabled one?

These questions are often confused. Without arguing for it I will here simply assert and accept that the answer to the first question is an emphatic 'yes'. It is an assumption of this paper that it is wrong to show preference for a non-disabled person over a disabled one in any way that denies that both are equally entitled to the sante concern, respect and protection as is accorded to any citizen. For such preference would imply that the disabled person was somehow less than an equal in moral and/or political terms. (We are only talking of preferences which carry this implication. Thus a preference for a brain surgeon without Parkinson's disease is not a preference which assaults the dignity of those with this damaging condition.) 
The crucial question is the second one. Is it wrong to prefer to produce or to prefer to be a non-disabled individual rather than a disabled one? (Compare the questions: 'is it wrong to prefer to be a woman or to prefer to be a Jew or to prefer to be black?') Would such a preference violate the principle of equality implicit in the first question and accepted by this author?

\section{Should we attempt to prevent disability?}

To try to resolve the question of the ethics of attempting to prevent disability we might well begin by examining a series of questions which look at the different means by which we might make this attempt, to see what light this throws on the ethics of different courses of action. I will list them first and then discuss each briefly.

Is it wrong to prefer to produce a non-disabled child and attempt to achieve that preference:

(a) by wishing?

(b) by behaviour modification?

(c) by postponement of conception?

(d) by therapy (including gene therapy)?

(e) by selecting between pre-implantation embryos?

(f) by abortion?

(g) by infanticide?

Is it wrong to wish that one's child (or, for that matter, oneself or one's friends) will not be disabled in any way? Is it wrong to wish this full-heartedly knowing that the making of the wish, perhaps publicly, might be thought by some to constitute an attack on people with disability? And if it is not wrong to wish for the healthy child in this fullhearted sense, would it be wrong, if we had the power, to play fairy godmother to ourselves and grant our wish? Of course, in wishing that my child will not be disabled I am not committing myself to the view that should it none the less be born disabled, it would then have a life not worthy to be lived. I am saying that it is better in some sense that my child be not disabled, but not that if it is disabled a non-disabled child is a better child. These are of course, different senses of 'better'.

Now reverse this suggestion. What would we think of someone who wished that her child be born disabled rather than healthy? Would a decent person wish to have a disabled child? Would a decent person try to grant their own wish? Some apparently decent deaf people do in fact wish their children to be deaf like them, and resist therapies to improve the hearing of their children. They suggest that there is a distinctive deaf culture which is in some senses better than that available to those with hearing. Perhaps the test here is whether or not we would feel a deaf parent justified in deliberately taking steps to ensure that a future child would be conceived with deafness genetically guaranteed in order to ensure that it had secured to it the benefits of deaf culture. Would we accept that this was a morally neutral piece of 'medical' intervention (perhaps like male circumcision-if that is morally neutral?) or rather a deliberate disabling or 'mutilating' act?

Suppose a woman is contemplating attempting to conceive and she knows that if she continues consumption of alcohol and, say, smoking, she is likely to disable her child in some way. Should she stop these things and modify her behaviour so as to maximize the chances of her child not being disabled? Again I believe she should, and 
that she would be wrong not to-wrong, because to fail to modify her behaviour would be to deliberately risk disabling her child.

Let's look at postponement of conception and gene therapy together. The same arguments would apply. Suppose a woman could, by therapy in utero, remove disability, should she do so? We think, I think, that she should-for reasons analogous to those above. Now suppose she is affected by a condition which will disable any child she conceives now, but if she postpones conception and takes a course of treatment she can conceive normally. Ought she to postpone conception in order to avoid having a disabled child? Again, we think she should act so as to avoid having a disabled child, even where the child she will have after treatment will not be 'made better' by the treatment and will not be the same as the child she would have had but for the treatment. In other words, we still believe that she would be right to act so that she has a healthy rather than a disabled child, although it involves choosing between possible children rather than making one child well. ${ }^{1}$

Suppose, as is in fact normal practice, a woman using in vitro fertilization techniques (TVF) has had five eggs fertilized in vitro and now wishes to use her embryos to become pregnant. Normal practice would be to insert two embryos, or at most three. This is because insertion of two or three embryos maximizes the chances of one successful pregnancy and hence one live birth; and inserting no more than three minimizes the chances of multiple pregnancy, which would probably decrease the chance of getting even one live birth. Suppose pre-implantation screening had revealed two of the embryos to possess disabilities of one sort or another. Would it be right to insert the two embryos with disability or to choose randomly which embryos to implant? Would only 'a bad scientific ethics' suggest that it would be wrong to implant the two embryos with disability and thus deliberately choose to have a disabled rather than a healthy child? Would we applaud the actions of a doctor who overrode the mother's wishes in such a case and deliberately implanted the embryos with disability?

\section{The justification is not the reason}

But notice that in the justification for declining to implant particular embryos, disability plays no role at all. The mother would be entitled to decline to implant even healthy embryos. Her reason for not implanting these particular embryos may be that they are disabled, but her justification is in terms of her entitlement to decline to implant any at all, disabled or not. For example, a woman's reason for choosing an abortion may be that she does not want to run risks to her health, but the justification must be that the moral importance, the moral status of the embryo, is not such as to require those risks of her. (It is just this point about the moral importance of the embryo about which those who accept and those who reject abortion disagree.)

The conclusions we have so far reached are unsurprising. Of course they are predicated on the idea that disability is somehow disabling and therefore undesirable. If it were not, there would be no motive to try to cure or obviate disability in health care more generally. If we believe that medical science should try to cure disability where possible and that parents would be wrong to withhold from their disabled children cures as they become available, then we will be likely to agree in our answers to questions (a) to (e) above. 


\section{What is disability?}

It is notoriously hard to give a satisfactory definition of disability. ${ }^{2} \mathrm{~A}$ disability is surely a physical or mental condition we have a strong rational preference not to be in; it is, more importantly, a condition which is in some sense a 'harmed condition'. ${ }^{3}$ I have in mind the sort of condition which, if a patient presented with it unconscious in the casualty department of a hospital and the condition could be easily and immediately reversed, but not reversed unless the doctor acts without delay, a doctor would be negligent were she not to attempt reversal. Or, one which, if a pregnant mother knew that it affected her fetus and knew also she could remove the condition by simple dietary adjustment, then to fail to do so would be to knowingly harm her child. This goes for relatively minor conditions like the loss of a finger, or deafness, and also for disfiguring conditions right through to major disability like paraplegia.

To make clearer what's at issue here, let's imagine that as a result of industrial effluent someone had contracted a condition that they felt had disabled or harmed them in some sense. How might they convince a court, say, that they had suffered disability or injury?

The answer is obvious but necessarily vague. Whatever it would be plausible to say in answer to such a question is what I mean (and what is clearly meant) by disability and injury. It is not possible to stipulate exhaustively what would strike us as plausible here, but we know what injury is and we know what disability or incapacity is. If the condition in question was one which set premature limits on their lifespan-made their life shorter than it would be with treatment-or was one which rendered them specially vulnerable to infection-more vulnerable than others-we would surely recognise that they had been harmed, and perhaps to some extent disabled. At the very least such events would be plausible candidates for the description 'injuries' or 'disabilities'.

Against a background in which many people are standardly protected from birth or before against pollution hazards and infections, and have their healthy life expectancy extended, it would surely be plausible to claim that failure to protect in this way constituted an injury and left them disabled. Because of their vulnerability to infection and to environmental pollutants there would be places it was unsafe for them to go, and people with whom they could not freely consort. These restrictions on liberty are surely at least prima-facie disabling, as is the increased relative vulnerability.

These points are crucial because it is sometimes said that while we have an obligation to cure disease-to restore normal functioning-we do not have an obligation to enhance or improve upon a normal healthy life: that enhancing function is permissive, but could not be regarded as obligatory. But, what constitutes a normal healthy life is determined in part by technological and medical and other advances (hygiene, sanitation, etc.). It is normal now, for example, to be protected against tetanus, and the continued provision of such protection is not merely permissive. If the AIDS pandemic continues unabated and the only prospect, or the best prospect, for stemming its advance is the use of gene therapy to insert genes coding for antibodies to HIV, I cannot think that it would be coherent to regard making available such therapy as permissive rather than mandatory. ${ }^{4}$

This is not an exhaustive definition of disability, but it is a way of thinking about it which avoids certain obvious pitfalls. Firstly, it does not define disability in terms of any conception of normalcy. Secondly, it does not depend on post hoc ratification by the subject of the condition-it is not a prediction about how the subject of the condition will feel. This is important because we need an account of disability we can 
use for both the potentially self-conscious-gametes, embryos, fetuses and neonatesand the temporarily unconscious which does not wait upon subsequent ratification by the person concerned.

\section{Disability and the disabled}

The last two questions on our list concern abortion and infanticide for disability. It is often said by those with disability or by their supporters (who should of course include us all) that abortion for disability, or failure to keep disabled infants alive as long as possible, or even positive infanticide for disabled neonates, constitutes discrimination against the disabled as a group-that it is tantamount to devaluing them as persons, ${ }^{5}$ to devaluing them in some existential sense. Alison Davis identifies such talk with utilitarianism and comments further that "[i]t would also justify using me as a donor bank for someone more physically perfect ( I am confined to a wheelchair due to spina bifida) and, depending on our view of relative worth, it would justify using any of us as a donor if someone of the status of Einstein or Beethoven, or even Bob Geldof, needed one of our organs to survive'. ${ }^{6}$ This is a possible version of utilitarianism of course, but not, I believe, one espoused by anyone today. On the view assumed in this paper and which I have defended in detail elsewhere, ${ }^{7}$ all persons share the same moral status whether disabled or not. To decide not to keep a disabled neonate alive no more constitutes an attack on the disabled than does curing disability. To set badly broken legs does not constitute an attack on those confined to wheelchairs. To prefer to remove disability where we can is not to prefer non-disabled individuals as persons. To reiterate, if a pregnant mother can take steps to cure a disability affecting her fetus she should certainly do so, for to fail to do so is to choose to handicap her child. She is not saying that she prefers those without disability as persons when she says she would prefer not to have a disabled child.

I have said that the decision not to keep a disabled neonate alive and the decision to abort for disability no more constitute attacks on the disabled than does curing disability. I believe this to be true, but its truth depends upon the moral status of the fetus and the neonate being the same as that of the embryo and the gametes, and not the same as human individuals who have developed the capacity to value their own existence-persons, I believe, properly so called. I have developed this argument in detail elsewhere, ${ }^{8}$ and here I will simply summarise it. For the conclusions I want to draw do not depend upon the truth or cogency of the argument, but rather on the shared morality of which the argument (whichever side of it is taken) is a part.

\section{The moral status of human individuals}

If it is wrong deliberately to implant, say, severely disabled pre-implantation embryos rather than healthy ones, or if it is permissible to abort a fetus in order to save the life of or preserve the health of its mother, then there must be a morally significant difference between the moral status of the embryo or the fetus and that of the mature aduit. Most people believe that there is some such difference, and no one could accept abortion under any circumstances (save randomly, where either the mother or the fetus can live but not both) ${ }^{9}$ without accepting some version of the thesis that there is a morally significant difference between the fetus and its mother. My own suggestion is 
that the moral status of the embryo, the fetus, the neonate and, indeed, any individual is determined by its possession of those features which make you or me morally more important than cats or canaries. At no stage of its development does the human embryo, fetus or neonate possess features that relevantly distinguish it from cats and canaries-save two. They are species membership and potential. Species membership however is devoid of moral significance; species preference is, like race or gender preference, simply a prejudice. Potential is no more helpful: whatever potential is possessed by the human embryo is also possessed by the unfertilized egg and the sperm, and so the argument that we have an obligation to realize human potential becomes the exhausting and unattractive ethic of maximal procreation. ${ }^{10}$

On my account persons properly so called are individuals capable of valuing their own existence. This view, which makes features which depend upon the capacity for self-consciousness and a minimal rationality central, is like that of John Locke and many philosophers since. ${ }^{11}$ The important point is that a view like this distinguishes persons with such capacities from embryos, fetuses and neonates, not on the grounds of presence or absence of disability, but on the grounds of presence or absence of the capacities that make for moral significance.

So much for the summary of the argument. It is of course just that-a summary and not itself an argument. It will not convince those who disagree. The important point for present purposes, and one which bears repeating, is that the moral difference between the embryo, the fetus and the neonate depends at no point and in no part on possession or absence of disability. If pre-implantation embryos may be destroyed, if fetuses may be aborted or neonates allowed to die, the justification must be in terms of their moral status. Those, like myself, who argue that the neonate is not morally significantly different from the unfertilized egg on the one hand, and from cats and canaries on the other, owe an account of why this is so. ${ }^{12}$ Those who deny it also owe an account of why it is not so. I do not believe that disability is relevant to any of these accounts, whether from one side of the argument or the other.

That this is so can be seen from the other side of the argument. Alison Davis is a prominent defender of the rights of the disabled, but her defence is from a 'pro-life' perspective. On the pro-life view defended by Davis abortion is never justifiable, not even to save the life of the mother, nor however disabled the fetus is or how disabled the child which it will become will be. On this view the mother's life is of no more importance than that of the fetus, and both must be equally respected. On such a view abortion will be ruled our whether or not the fetus is disabled. In particular, and dramatically, abortion is ruled out if the fetus will have no chance of being carried to term, and even if the mother will die if it is not aborted. The individual who takes a view like this must argue that there is no justification for killing one morally important being to save the life of another where both are of equal status.

In the justification of a position like that of Alison Davis, handicap and disability play no role at all. Nor do they, or need they, in the justification of views from the other side. The moral status of no individual, whether embryo, fetus, neonate, human adult, nor cat, nor canary, is altered one jot by the existence or absence of disability.

\section{A life not worth living}

The notion of a life worth not living or a life not worthy to be lived is often invoked in discussions of disability. I do not believe that this notion plays any role at all in the 
justification of decisions not to produce a disabled child in the seven sorts of circumstances identified above. No-one, I believe, would say that the lives of most people with disability are not worth living. All that is claimed is that it would be better not to have a disability-if it would not, then it would not be a disability. None of the decisions not to produce a disabled individual depend on making the judgement that that individual's life would be not worth living or that disabled individuals are not worthy to live-a rather different point often confused with the alternative formulation.

If, say, I were to lose the use of my legs and become disabled to that extent (or for that matter to succumb to some mental disability or illness), 1 would regard it as a severe misfortune, perhaps even a tragedy, but I would not have become less valuable in the 'existential' sense or less morally important on that account. My life would be no more nor less subordinate to those not disabled than it was before. I hope I would find life still worth living; and, if I did, this would not change my views about the rightness of wishing for a child who was not paraplegic (or for example brain damaged, provided the damage left sufficient brain function for self-consciousness), nor about the rightness of acting on such a wish if I were able so to do. I have a rational preference to remain non-disabled, and I have that preference for any children I may have and, indeed, for humankind in general (and even for animals, for that matter). To have a rational preference not to be disabled is not the same as having a rational preference for the non-disabled as persons.

\section{Conclusion}

This brief paper has tried both to explain that we should try to eradicate disability, and to show why this view in no way implies or involves discrimination against handicapped people. I believe that the rightness of choosing not to produce disabled individuals in cases (a) to (e) above is so clear that it would be an embarrassment to any view to have to differ-although of course even embarrassments of this magnitude do not of themselves demonstrate the error of a position to which they attach.

Intuitions over the cases of abortion or infanticide are likely to be more divergent. I hope I have said enough to show that disagreements over the legitimacy of aborting disabled fetuses (permitted by legislation in most countries of the European Union) are disagreements about the legitimacy of abortion and not about attitudes to disability. Infanticide, more problematic certainly, involves an extension of the same argument. Those who argue that it should be permitted do so because they see no morally relevant difference between neonates and fetuses; those who disagree must show what morally relevant differences obtain. But again these differences will have nothing to do with the presence or absence of disability.

A practical example can help us here. The United Kingdom Human Fertilization and Embryology Act (1990) permits abortion to prevent fetal handicap up to birth. Since there can be no difference, moral or physical, between a fetus killed en ventre sa mere at 27 weeks 55 minutes, and one killed as a neonate one minute later, it cannot be a great leap of morality to at least question whether, if the abortion is morally legitimate, the infanticide might not also be morally legitimate. The same minute difference also shows that the operative justification for killing the fetus but not the neonate had in fact nothing to do with the level of disability or even the presence of disability, but rather involved prior acceptance of the legitimacy of abortion rather 
than infanticide (however ethically confused such acceptance might be). That is to say, the moral justification for accepting fetal handicap as a reason for abortion right up to term depends upon the judgement that abortion is permissible-justifiable-in a way that infanticide is not; that it is justifable, that is, in a way that admits of the consideration of a reason. The judgement that abortion can be justifiable is thus prior to the consideration of particular reasons for abortion in a given case. The fact of handicap or disability plays no role in that prior judgement. The reasons for abortion in the particular case are only considered because a judgement has already been made that abortion is permissible. In that prior judgement disability plays no part. This is shown by the fact that in the case of infanticide for disability, though the reason (the disability) is as strong as formerly, the justification for infanticide is clearly felt to be absent.

This paper has attempted to explain how abortion and even infanticide for disability are extensions of the legitimate, perhaps imperative, ethic of combatting disability. In particular, that it is on a continuum, unbroken by any distinction of ethical significance, with attempts to eradicate disability by wish fulfilment or by the implantation of non-disabled embryos. The significant distinction is that persons are morally important in a way that no other sorts of creatures are. Persons can be unjustly discriminated against in ways that non-persons can not. The only reason not to select healthy embryos or not to abort disabled fetuses is not because this would be unjust to the embryos or fetuses, but because it might be offensive to those disabled persons who felt that it either disvalued them as persons, or threatened their equal standing in some way.

\section{Objections of disabled people}

I recognise that this paper has not examined in any depth the objections of disabled people, but I can at least outline how I believe this real problem is to be approached.

There are two types of indirect costs to the disabled of combatting disability in the ways outlined in this paper. There are what might be termed 'subjective costs', that is costs in terms of the feelings of being disvalued aroused by attempts to prevent the existence of people like them. Then there are also more 'objective' indirect costs in terms of the ways in which a policy of combatting disability in the ways outlined might encourage people with disability to be less valued by the community at large and consequently to become the victims of discrimination.

While both these sorts of costs should be limited so far as is possible, they each present different problems. So far as what I have called subjective costs are concerned, if, as I have suggested, they are irrational or misconceived, then we must ask whether there can be an obligation to protect some people against inappropriate feelings that they may have, at the cost of real harm and possibly pain and suffering to those who must continue to be born with disabilities just so that existing disabled people be protected from inappropriate feelings of rejection. As we have noted, these feelings might be and perhaps are aroused not simply by attempts to eradicate disability in future people, but by therapies for disability in their fellows.

The second 'objective' sorts of harm are easier to deal with. We should certainly combat such unjust and unjustified discrimination against disabled people by all of a wide variety of means at our disposal, including legislation. 
I have said, and I repeat, that having a rational preference not to become disabled oneself and not to have children with disability is not the same as having a rational preference for the non-disabled as persons.

\section{Acknowledgments}

I am grateful to Mary Lobjoit and Charles Erin for helpful comments. The paper has also benefited from comments made when I presented a rather different paper: "Is gene therapy a form of eugenics?' at the Inaugural Congress of the International Association of Bioethics, Amsterdam, 5-7 October 1992, and when I presented an earlier version of this paper at the symposium 'Justice and Health', at the University of Copenhagen, 24-25 April 1993. In particular I am grateful to Dan Brock, Norman Daniels, Raanan Gillon, Sфren Holm, Douglas Maclean and Maurice de Wachter.

\section{References}

1 This is Derek Parfit's example: see Parfit, D., 1976, Rights, interests and possible people. Moral Problems in Medicine, edited by S. Gorovitz (Englewood Cliffs, NJ: Prentice Hall). See also my discussion of this and related issues in Harris. J., 1992, Wonderwoman and Superman: Ethics and Human Biotechnology (Oxford University Press), Chap. 3.

2 The argument of most of this section first appeared in Harris, J., 1993, Is gene therapy a form of eugenics? Bioethics, 7(2/3), 178-188. I have taken the liberty of quoting from myself here, and apologize to anyone familiar with these few paragraphs.

3 See my discussion of the difference between harming and wronging in Harris, J., 1992, Wonderwomant and Superman: Ethics and Human Biotechnology (Oxford University Press), Chap. 4.

4 In this sense the definition of disability is like that of 'poverty'. Here my discussion of these issues is identical with my discussion of the same points in Harris, J., 1993, Is gene therapy a form of eugenics? Bioethics, 7(2/3), 178-188.

5 When I talk of valuing individuals in an existential sense-valuing an individual 'as a person'-I am talking of the dimension of the individual which entitles them to equal concern, respect and protection, which speaks to the issue of their dignity and standing with equal moral and political claims. I have analysed this notion at some length in Harris, J., 1985, The Value of Life (London: Routledge), Chap. 1.

6 Davis, A., 1988, p.150.

7 See Harris, J., 1985, The Value of Life (London: Routledge), Chap. 1; and Harris, J., 1994, Not all babies should be kept alive as long as possible. Principles of Health Care Ethics, edited by R. Gillon (London: Wiley), pp.643-657.

8 See Harris, J., 1985, The Value of Life (London: Routledge); Harris, J., 1992, Wonderwoman and Superman: Ethics and Human Biotechnology (Oxford University Press).

9 Judith Thomson's famous article is unpersuasive on the subject of self defence because it does not adequately show why the fetus is not entitled to defend itself. See Thomson, J. J., 1971, A defence of abortion. Philosophy and Public Affairs, 1(1), 000-000.

10 This is unattractive particularly to women, though not indefensible on that ground alone. There are, however, other grounds for rejecting it. See Harris, J., 1985, The Values of Life (London: Routledge), Chap. 1.

11 Locke, J., 1962, An Essay Concerning Human Understanding (London: Oxford University Press), Book II, Chap. 27.

12 I have given one such account in Harris, J., 1985, The Value of Life (London: Routledge); and Harris, J., 1992, Wonderwoman and Superman: Ethics and Human Biotechnology (Oxford University Press). 
Author

John Harris is Professor of Bioethics and Applied Philosophy in the School of Education and Research Director of the Centre for Social Ethics and Policy at the University of Manchester, Oxford Road, Manchester M13 9PL, UK. He is a member of the Ethics Committee of the British Medical Association, and has acted as ethical advisor to parliamentary bodies, interest groups and the media in the UK and Europe. $\mathrm{He}$ is currently director of 'AIDS: Ethics, Justice and European Policy', a European Commission research project involving 14 countries. 